\section{Virtually Yours}

Unfortunately, COVID-19 continues to disrupt our lives. As I am sure all of you know, M\&M 2021 will again, and hopefully for the last time, be entirely virtual. Talks will be recorded with "live" Q\&A sessions associated with each symposium. For M\&M 2020 this format worked well, with many lively discussions during the Q\&A sessions.

Even though we will miss the opportunity to greet each other in person and socialize, Program Chair Liz Wright and her excellent committee have put together an outstanding program with two pre-meeting congresses and two Sunday short courses. Pre-meeting congresses include the annual "Congress for Students, PostDocs and Early Career Professionals in Microscopy and Microanalysis" event, as well as a congress addressing "Recent Developments in Advanced Imaging and Spectroscopy." Sunday Short Courses include "Guidelines for Performing 4D-STEM Characterization" and an interactive course on "Data Analysis in Materials Science." The meeting itself will feature three plenary speakers. The Physical Science Plenary speaker will be Dr. Ondrej Krivanek, who will speak on his work on sub-angstrom resolution and chemical analysis using electron beams. The Biological Science Plenary speaker stage will be shared by Drs. Kizzmekia Corbett and Jason McLellan, who will discuss their work on development of the COVID19 vaccines. For more on Dr. McLellan, please see the Pioneers in Microscopy article in this issue. Even with the limitations of a virtual meeting, there will be nearly 1,150 presentations during the week, covering a wide range of topics including equipment development and biological and materials science applications that rely on microscopy and microanalysis technology. In addition to the many platform and poster presentations, there will also be a virtual exhibit hall where attendees can interact with exhibitors in chat rooms, demonstrations, and tutorials.

If you have not already done so, please register at Welcome | M\&M 2021 Microscopy \& Microanalysis (https://www.microscopy.org/MandM/2021).

\section{Robert L. Price}

Editor-in-Chief

\section{Publication Objective: to provide information of interest to microscopists.}

Microscopy Today is a controlled-circulation trade magazine owned by the Microscopy Society of America that is published six times a year in the odd months. Editorial coverage spans all microscopy techniques including light microscopy, scanning probe microscopy, electron microscopy, ion-beam techniques, and the wide range of microanalytical methods. Readers and authors come from both the life sciences and the physical sciences. The typical length of an article is about 2,000 words plus figures and tables; feature articles are longer. Interested authors should consult "Instructions for Contributors" on the Microscopy Today website: www.microscopy-today.com.

\section{ISSN 1551-9295}

\section{Disclaimer}

The Microscopy Society of America and the editors cannot be held responsible for opinions, errors, or for any consequences arising from the use of information contained in Microscopy Today. The appearance of advertising in Microscopy Today does not constitute an endorsement or approval by the Microscopy Society of America of any claims or information found in the advertisements. By submitting a manuscript to Microscopy Today, the author warrants that the article is original or that the author has written permission to use copyrighted material published elsewhere. While the contents of this magazine are believed to be accurate at press time, neither the Microscopy Society of America, the editors, nor the authors can accept legal responsibility for errors or omissions.

\section{Editorial Staff}

Robert L. Price, Editor-in-Chief bob.price@uscmed.sc.edu (803) 216-3824

Gennifer Levey, Production Manager glevey@meridianartpro.com (212) 780-0315

Beverly Maleeff, Administrative Editor bev@alumni.psu.edu

Charles E. Lyman, Senior Editor

charles.lyman@lehigh.edu

Phil Oshel, Senior Editor

oshel1pe@cmich.edu

Stephen Carmichael, Columnist

carmichael.stephen@mayo.edu

John Shields, Columnist

johnshields59@gmail.com

Cameron Varano, Pioneers Editor

cvarano@psu.edu

Richard Edelmann, Education Editor

edelmare@miamioh.edu

Deb Kelly, Microscopy 101 Editor

debkelly@psu.edu

Rich Fiore, Product and Industry News Editor rich@scifisalesinc.com

Rich Martens, Calendar Editor

atomman22@gmail.com

Nikolaus Cordes, Digital Content Editor

nikolaus.cordes@inl.gov

Thomas Kelly, Chief Innovation Judge

thomas.kelly@ametek.com

Robert Simmons, Chief Micrograph Judge

robert.simmons@briarwillow.com

Advertising Sales

M.J. Mrvica Associates, Inc.

2 West Taunton Avenue, Berlin, NJ 08009

mjmrvica@mrvica.com

(856) 768-9360

Kelly Miller, Account Manager

kmiller@mrvica.com

Magazine website:

http://www.microscopy-today.com

Free subscriptions are available.

Publisher

Cambridge University Press

One Liberty Plaza, 20th Floor

New York, New York 10006

(212) $337-5000$

Circulation: 18,000

Editorial Board

Nasim Alem, Penn State University

Arlan Benscoter, Lehigh University

John Bozzola, Southern Illinois University

Peter Crozier, Arizona State University

Vinayak Dravid, Northwestern University

David Grubb, Cornell University

Bryan Huey, University of Connecticut

Heather Lowers, U.S. Geological Survey

John Mackenzie, North Carolina State Univ.

Paul Maddox, U. of North Carolina-Chapel Hill

Ania Majewska, U. Rochester Med School

Joseph Michael, Sandia National Labs

Caroline Miller, Indiana University

Brian M. Patterson, Los Alamos National Lab

John Reffner, John Jay College, SUNY

Ian Robertson, University of Wisconsin

Phillip Russell, Appalachian State University

Bradley Thiel, SUNY Polytechnic Institute

Simon Watkins, University of Pittsburgh

Cynthia Zeissler, Nat. Inst. of Stds. and Tech. (NIST) 